\title{
First outbreak of Clostridium difficile infections in Serbia: An experience of the department for orthopedic surgery
}

\author{
Biljana Mijović*1,2, Ljiljana Marković-Denić ${ }^{3}$, Dusica Banković-Lazarevićc ${ }^{4,5}$, Maja Račić ${ }^{1}$ \\ ${ }^{1}$ Department of primary health care and public health, Faculty of Medicine, Foča, University of East Sarajevo, Bosnia and \\ Herzegovina \\ ${ }^{2}$ Public Health Institute, Užice, Serbia \\ ${ }^{3}$ Faculty of Medicine, University of Belgrade, Serbia \\ ${ }^{4}$ Public Health Institute "Dr Milan Jovanović Batut", Belgrade, Serbia \\ ${ }^{5}$ Faculty of Dentistry, Pancevo, Serbia
}

Received: October 24, 2018

DOI: $10.5430 /$ jer.v5n1p50
Accepted: February 19, $2019 \quad$ Online Published: March 7, 2019

URL: https://doi.org/10.5430/jer.v5n1p50

\begin{abstract}
Objectives: Increased C. difficile infection rates were observed during the last decade, as well as the onset of complicated forms of the disease. The primary objective of this study was to report the first outbreak of C. difficile in a Serbian hospital, aiming to determine clinical and environmental factors associated with the outbreak. The secondary objective was to describe outbreak control measures taken.

Design: The retrospective cohort study conducted from 18 April to 22 May 2013 in Serbian healthcare. Ninety-five patients hospitalized at the Department for orthopedic surgery during the CDI outbreak.

Results: Prophylactic antibiotic therapy was identified among $93.3 \%$ patients with and $87.9 \%$ without C. difficile infection. The multivariate logistic regression analysis has shown that the independent risk factors for $\mathrm{C}$. difficile infection incidence are the age beyond $70(\mathrm{OR}=4.5 ; 95 \% \mathrm{CI}=1.1-18.2 ; p=.031)$ and the length of antibiotic therapy $(\mathrm{OR}=1.5 ; 95 \% \mathrm{CI}=1.1-2.1 ; p=.017)$. Conclusion: The length of antibiotic prophylaxis is linked with the incidence. Orthopedic departments have a risk of C. difficile infection. Infection control measure, antimicrobial stewardship programs and compliance to guidelines for the prescribing of antibiotics play important role in the prevention of C. difficile infection burden.
\end{abstract}

Key Words: Clostridium difficile infection, Epidemic, Risk factors, Disease outbreak, Prevention

\section{INTRODUCTION}

Clostridium difficile (C. difficile) is one of the most common causes of nosocomial gastrointestinal infections. ${ }^{[1]}$ Increased C. difficile infection (CDI) rates were observed during the last decade, as well as the onset of complicated forms of the disease. Information on the incidence of these infections varies from one country to another. On the global level, it has been estimated that the incidence has almost doubled, from 5.5 per 10,000 in the year 2000 , to 11.2 per 10,000 in the year 2005 in the USA. ${ }^{[2]}$ In Canada, the incidence rate increased

\footnotetext{
*Correspondence: Biljana Mijović; Email: biljana.mijovic@ gmail.com; Address: Department of primary health care and public health, Faculty of Medicine, Foča, University of East Sarajevo, Bosnia and Herzegovina.
} 
from 6 per 1,000 hospital admissions in 1997 to 22.5 in 2004, while the mortality rate increased from $1.5 \%$ to $6.9 \% .{ }^{[3]}$ Contributing factor to the dramatic change in the epidemiology of CDI was the emergence of hypervirulent strains, such as ribotype 027 (NAP1/BI/027), which is responsible for the great numbers of outbreaks, first in the United States and Canada, and then also in Western Europe. ${ }^{[3-5]}$ This stain is still dominant in the EU countries ${ }^{[6,7]}$ as in the countries neighboring Serbia. ${ }^{[8]}$ The first single cases of C. difficile associated diarrhea have been officially reported in Serbia in 2011. ${ }^{[9]}$ In 2013, 63 cases died of CDI, while CDI accounted for $13 \%$ of all hospital infections. Twenty-one CDI nosocomial outbreaks with 163 cases have been reported this year in the country. ${ }^{[10]}$ This study decribes the first outbreak of C. difficile in a Serbian hospital, aiming to determine clinical and environmental factors associated with this outbreak and to describe the outbreak control measures taken.

\section{MethodS}

\subsection{Study design}

Retrospective cohort study.

\subsection{Study setting and data collection}

The study was conducted in General Hospital Uzice, a 750bed secondary care facility, located in the central-eastern part of Serbia (an estimated population area of about 340,000 inhabitants). The hospital's medical services included 24-hour in-house physicians of various specialties, nurses, laboratory, radiology department and pharmacy. Day, night shifts and weekends were covered by rotating full-time hospitalists and nurses. The study included 98 patients who were hospitalized at the Department for orthopedic surgery, during the CDI outbreak, recorded from 18 April to 22 May 2013. To describe this outbreak, an infection control team (Antibiotic stewardship staff) collected clinical and microbiological data for each patient using a standardized epidemiological questionnaire. Data on potential disease, risk factors, daily progress notes, medical information, and outcomes were obtained from the hospital records or by surveying the patients. The data included age, gender, date of admission, risk factors for CDI, date of CDI onset and outcome.

\subsection{Definitions}

To be diagnosed as a hospital-associated CDI case, patient had to have diarrheal stools or toxic megacolon, and a positive laboratory assay for C. difficile toxin A and/or B in stools or a toxin-producing $\mathrm{C}$. difficile organism detected in stool. Diarrhea was defined as a presence of three or more episodes of loose bowel movement per a 24-hour period, or more frequently than is usual if the individuals had no other recognizable etiology (e.g. laxative use). Diarrhea related Published by Sciedu Press to CDI had to last at least 48 hours or more after hospital admission. If patients had diarrhea that began within 48 hours of hospital admission, the etiology was considered community-acquired and these patients were excluded from the study. ${ }^{[11]}$

\subsection{Laboratory diagnosis of $\mathrm{C}$. diffiicile infections}

Enzyme-linked immunoassay (VIDAS C. difficile Toxin A/B) was used to examine stool specimens for toxin A and B. A minimum of $2.0 \mathrm{ml}$ of diarrheal stool was collected in sterile watertight container and stored at $2^{\circ} \mathrm{C}$ to $8^{\circ} \mathrm{C}$ until tested. Each container was labeled with patient's name, date and actual time of collection. All specimens were tested within two days of collection. Immunoassays were primary carried out in General hospital Uzice, then sent for confirmation and further microbiological analyses to the CDI national reference laboratory in the Public Health Institute, Niš. Antimicrobial resistance was determined by disk diffusion method according to CLSI standard recommendations (medium Clo Agar, BioMerieux). Commercially prepared disks, impregnated with standard concentration of antibiotics were evenly dispensed onto the agar surface.

To analyze if medical equipment and work surfaces have been contaminated with C.difficile, the staff of Public Health Institute Uzice took the daily swabs from the most critical locations (operating tables, kitchen, wet areas, areas with high levels of staff activity) and hospital staff's hands by parallel spaced and perpendicular stripes. The size of area sampled was at least $100 \mathrm{~cm}^{2}$. The samples were kept at $4{ }^{\circ} \mathrm{C}$ before being transported to the laboratory for testing. The swabs were transferred to agar plate medium for C.difficile

\subsection{Statistical analysis}

Data analysis was performed using SPSS ver. 17.0 software (SPSS Inc., Chicago, IL, USA) using methods of descriptive and analytical statistics. Risk assessment was measured by the Student-t test, Chi-square test and Fisher's exact probability test. Univariate logistic regression analysis was performed to identify risk factors. Nosocomial diarrhea with proven C.difficileconsidered as a dependent variable. The risk factors for which the univariate analysis gave $p<.1$ were included in multivariate analyses using conditional multiple logistic regression.

\section{Results}

The index case of this outbreak was detected on 18th April, and the last one on 22 May 2013. During this period, a total of 98 patients were treated at the Department for orthopedic surgery of the General Hospital Uzice. Eighteen orthopedic patients with diarrhea were identified. Out of 
these, 15 were laboratory confirmed nosocomial CDI infection $(15.3 \%)$. Chronological distribution of the disease is shown in Figure 1. Out of 15, three patients died in the hospital, so the 30 -day CDI case-fatality ratio was $20 \%$. In the observed cohort, a total of $14(93.3 \%)$ patients underwent surgery and all but one was placed in an intensive care unit. The results of the univariate logistic regression analysis are shown in the Table 1 . Significantly more people older than 70 years were in the group of patients with nosocomial $\mathrm{CDI}(\mathrm{OR}=4.7 ; 95 \% \mathrm{CI}=1.2-18.0 ; p=.023)$. There were no gender differences between nosocomail CDC and non
CDI cases $(p=.976)$, nor were comorbidities such as diabetes $(p=.948)$ and hypertension $(p=.090)$ linked with CDI. Prophylactic antibiotic therapy was identified among $14(93.3 \%)$ patients with CDI and $87.9 \%$ without CDI. The most commonly implicated antibiotics were beta-lactams. The duration of antibiotic exposure was longer in patients with CDI ( $p=.017)$ (see Table 1). The multivariate logistic regression analysis showed that the independent risk factors for CDI incidence are the age beyond $70(\mathrm{OR}=4.5 ; 95 \% \mathrm{CI}$ $=1.1-18.2 ; p=.031 ;)$ and the length of antibiotic therapy $(\mathrm{OR}=1.5 ; 95 \% \mathrm{CI}=1.1-2.1 ; p=.017)$ (see Table 2$)$.

Table 1. Potential risk factors for CDI at the Orthopedic Department of the General Hospital Uzice, univariate logistic regression

\begin{tabular}{lllll}
\hline Risk factors & $\begin{array}{l}\text { CDI cases (\%) } \\
(\mathbf{N}=\mathbf{1 5})\end{array}$ & $\begin{array}{l}\text { Non-CDI cases (\%) } \\
(\mathbf{N}=\mathbf{8 3})\end{array}$ & OR (95\% CI) & $\boldsymbol{p}^{*}$ \\
\hline Demographics and comorbidities & & & & \\
Age $\geq 70$ & $12(80)$ & $38(45.7)$ & $(1.2-18.0)$ & $.023 *$ \\
Female gender & $10(66.6)$ & $55(66.2)$ & $1.0 .(0.3-3.2)$ & .976 \\
Diabetes & $3(25)$ & $16(19.2)$ & $1.0(0.2-4.1)$ & .948 \\
Hypertension & $9(60)$ & $30(36.1)$ & $2.6(0.8-8.1)$ & .090 \\
Medical procedures & & & $0.8(0.2-3.5)$ & .859 \\
Urinary catheter placement & $12(80)$ & $68(81.9)$ & $2.3(0.2-19.6)$ & .426 \\
Surgical intervention & $14(93.3)$ & $71(85.5)$ & $2.6(0.3-21.5)$ & .376 \\
The admission to intensive care unit & $14(93.3)$ & $70(84.3)$ & $3.0(0.3-25.3)$ & .294 \\
Surgical drain & $14(93.3)$ & $68(81.9)$ & $1.9(0.2-16.1)$ & .550 \\
Antibiotic prophylaxis & $14(93.3)$ & $73(87.9)$ & $1.5(1.1-2.1)$ & $.017 *$ \\
Length of antibiotic prophylaxis (days) & $3.6 \pm 2.0$ & $2.4 \pm 1.4$ & $1.3(0.3-4.5)$ & .654 \\
Ceftriaxone & $11(78.5)$ & $56(67.4)$ & & \\
\hline
\end{tabular}

Note. CDI- Clostridium difficille infection; OR-odd ratio; ${ }^{*} p<.05$.

Table 2. Potential risk factors for CDI incidence at the Orthopedic Department of the General Hospital Uzice, multivariate logistic regression

\begin{tabular}{lllll}
\hline \multirow{2}{*}{ Risk factors } & CDI cases (\%) & Non-CDI-cases (\%) & OR (95\% CI) & P \\
\hline N = 15 & $12(80)$ & $38(45.7)$ & $4.5(1.1-18.2)$ & .031 \\
\hline Age $\geq 70$ & $3.6 \pm 2.0$ & $2.4 \pm 1.4$ & $1.5(1.1-2.1)$ & .017 \\
\hline
\end{tabular}

Note. CDI- Clostridium difficille infection. OR-odd ratio

\section{Discussion}

We have described the CDI outbreak at the Department for orthopedic surgery of the General Hospital Uzice, which was the first outbreak of the CDI reported in Serbia. This outbreak included 15 hospitalized patients with confirmed $\mathrm{CDI}$, with a high incidence rate $(15.3 \%)$, as well as the case fatality rate (20\%).
First CDI cases were detected in 2011 in our hospital, when the laboratory confirmation of these infections was introduced. During 2012, a total of 20 cases were reported (incidence rate was $1.34 / 1000$ patient-days). This outbreak in 2013 was the first large CDI outbreak not only in our hospital, but in the whole country. It posed considerable clinical, infection control and public health challenges. At that time, surveillance and control of health care-associated infections 
(HAI) were organized at specific way. Infection control team consisted of two infection control nurses employed in this hospital who worked in close cooperation with an infection control doctor (epidemiology specialist) from the responsible Institute of Public Health. Such organization of HAI surveillance is still applied in some hospitals in Serbia, although the Rule book of HAI requires the existence of a complete own HAI team in each hospital. ${ }^{[12]}$ However, due to our limited financial resources and the insufficient number of staff in hospitals, such organization of the HAI surveillance has been applied since 2001 when a national HAI surveillance system was established in Serbia. The members of the infection control team had a great experience in working together and, thanks to good coordination and communication with all staff in the hospital, managed to reach certain conclusions and take adequate anti-epidemic measures.

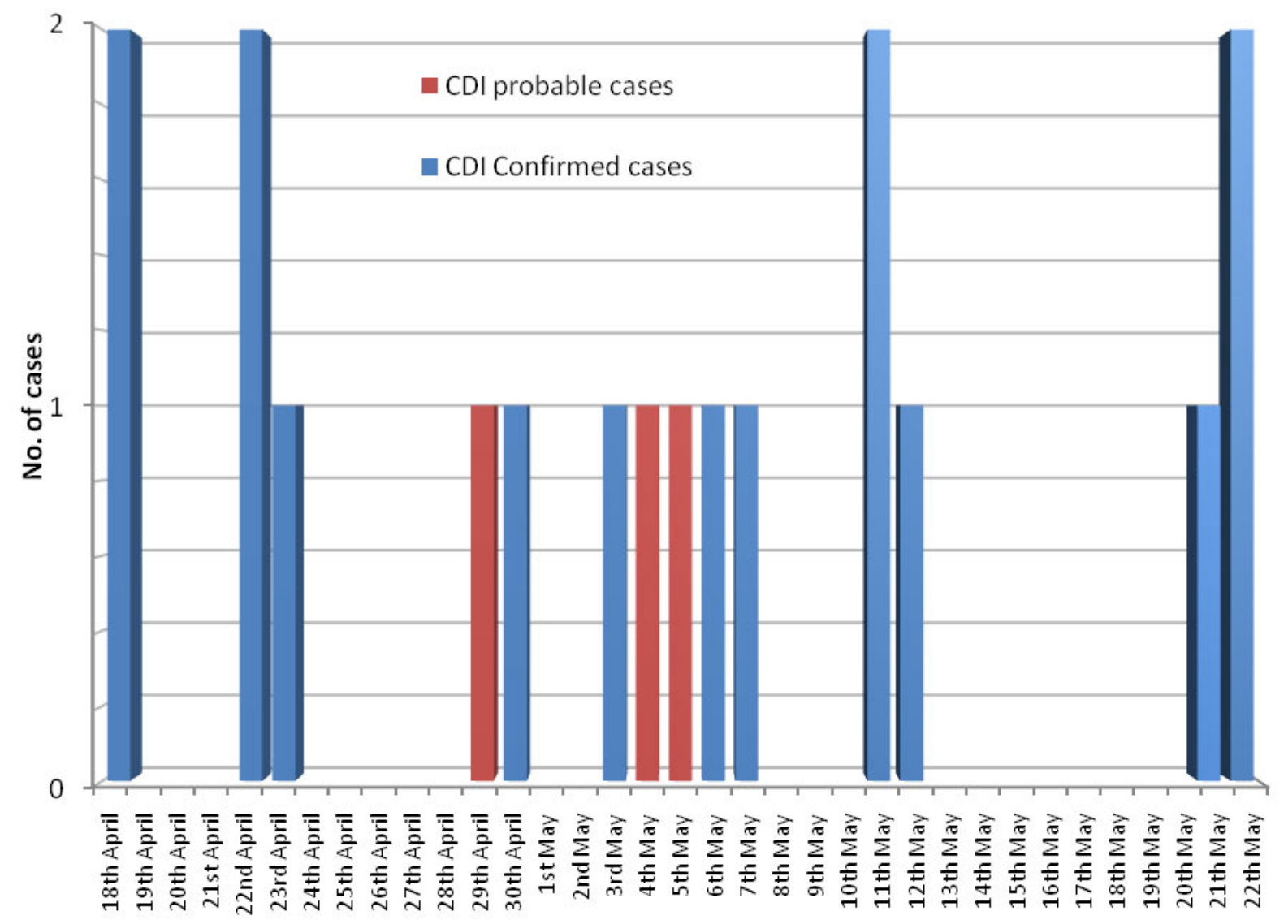

Figure 1. Health care-associated Clostridium difficile infections

Our results are similar to the results of other studies, showing that patients $\geq 70$ were around 4 times more likely to have CDI than younger individuals. ${ }^{[13,14]}$ It was shown during one outbreak that risk of CDI was 10 time higher among patients older than 65 years. ${ }^{[15]}$

It is well known that CDI development is usually preceded by the use of antimicrobial therapy, which alters the normal ratio of bacteria in the digestive tract. ${ }^{[16]}$ Almost all antibiotics have been associated with CDI, even the antibiotics used in the surgical prophylaxis. Development of CDI infections is frequently linked with the preoperative use of third-generation cephalosporins. It was identified that when multiple cefuroxime-based antibiotic prophylaxis in ortho- pedic surgery was switched to a single dose of gentamycin and flucloxacillin or teicoplanin for patients with methicillinresistant Staphylococcus aureus, the frequency of CDI significantly decreased. ${ }^{[17]}$ Although our study found no association between antibiotic therapy and CDI, the length of antibiotic prophylaxis was statistically significantly related to CDI incidence. The average length of antibiotic therapy in non-CDI patients was 2.3 days, and in CDI patients 3.8 days. This outbreak increased the vigilance of the surgeons and revealed the need for the application of current protocols and guideline for antibiotic prophylaxis in orthopedic surgery both in terms of the antibiotic class and the length of their use. Comorbidities, such as diabetes $(p=.630)$ and 
hypertension (0.141), were not related to CDI incidence. The study conducted by Suljagic et al. in Serbia also found no relation between diabetes and $\mathrm{CDI},{ }^{[13]}$ however, the knowledge of potential mechanisms for the increased risk of CDI in patients with diabetes are still limited. ${ }^{[18]}$

During this outbreak, a bundle of outbreak control measures were introduced including reinforcement of infection control measures, communication, optimization of diagnosis and CDI therapy, as well as, antimicrobial stewardship. Patients were placed in the single room at the beginning of the outbreak, and then, confirmed cases were followed in the patients' rooms in one part of the corridor. The hospital environment hygiene was improved and chlorine preparations disinfection with adequate contact time was introduced every eight hour shift. The staff was separated, and some of them take cared only for CDI cases. They were re-educated about hand washing and possible modes of CDI transmission. Patients' personal hygiene was also strictly maintained.

In April, when the outbreak was reported, the hospital was more crowded than usual. While the average number of hospitalized patients in other months was 72, in April it increased up to 129 . One of the special measures introduced was the suspension of cold case admission, which ultimately reduced the number of patients at the ward and contributed to a more balanced accommodation schedule. All rooms at the ward have four beds, which facilitated contact transmission.

Infection control team worked closely with staff in the responsible regional Institute of Public Health. Beside daily communication at regional level, well-established collaboration with policy-makers has existed. There are network of 25 regional public health institutes and one national Public health Institute.

This first outbreak of CDI in our country was a signal to the Serbian Ministry of Health to urgently issue Instruction for Prevention and Control of Hospital Infections caused by $\mathrm{C}$. difficile, which became mandatory for all health institutions in Serbia. ${ }^{[19]}$ The same instruction regulated the therapeutic according with international guidelines. ${ }^{[20,21]}$ Systematic reviews support the hypothesis that implementation of antimicrobial stewardship programs (ASP) could have the positive impact on the prevention of CDI outbreaks. ${ }^{[22,23]}$ The experiences from this outbreak indicate the need to conduct further research on the effectiveness of newly-implemented ASP in Serbia.

Limitation of this study was lack of genotyping of C. difficile due to some technical problems in National referent laboratory. However, lessons learned from this first CDI outbreak in Serbia were used by other healthcare institutions in prevention and taking control measures in further outbreaks.

\section{Conclusion}

The length of antibiotic prophylaxis is linked with CDI incidence. Orthopedic departments have a risk of CDI. Therefore, infection control measure, antimicrobial stewardship programs and compliance to guidelines for the prescribing of antibiotics play important role in the prevention of $\mathrm{C}$. difficile infection burden.

\section{REFERENCES}

[1] Jullian-Desayes I, Landelle C, Mallaret MR, et al. Clostridium difficile contamination of health care workers' hands and its potential contribution to the spread of infection: Review of the literature. Am J Infect Control. 2017; 45: 51-8. PMid:28065332. https://doi.org/10.1016/j.ajic.2016.08.017

[2] Zilberberg MD, Shorr AF, Kollef MH. Increase in adult Clostridium difficile related hospitalizations and case-fatality rate, United States, 2000-2005. Emerg Infect Dis. 2008 Jun; 14: 929-31. https : //doi.org/10.3201/eid1406.071447

[3] Loo VG, Poirier L, Miller MA, et al. A predominantly clonal multiinstitutional outbreak of Clostridium difficile-associated diarrhea with high morbidity and mortality. N Engl J Med. 2005 Dec; 353: 2442-9. https://doi.org/10.1056/NEJMoa051639

[4] McDonald LC, Killgore GE, Thompson A, et al. An epidemic, toxin gene-variant strain of Clostridium difficile. N Engl J Med. 2005 Dec; 353: 2433-41. https://doi.org/10.1056/NEJMoa051590

[5] Warny M, Pepin J, Fang A, et al. Toxin production by an emerging strain of Clostridium difficile associated with outbreaks of severe dis- ease in North America and Europe. Lancet. 2005 Sep; 366: 1079-84. https://doi.org/10.1016/S0140-6736(05)67420-X

[6] Davies KA, Ashwin H, Longshaw CM, et al, EUCLID study group. Diversity of Clostridium difficile PCR ribotypes in Europe: results from the European, multicentre, prospective, biannual, point prevalence study of Clostridium difficile infection in hospitalised patients with diarrhoea (EUCLID), 2012 and 2013. Eurosurveillance. 2016; 21: pii=30294. https://doi.org/10.2807/1560-7917.ES.2 016.21 .29 .30294

[7] ECDC. Clostridium difficile infections. Annual Epidemiological Report for 2016. European Centre for Disease prevention and Control, Stocholm, 2018. Available from: https://ecdc.europa.eu/sites/portal/files/document s/AER_for_2016-C-difficile.pdf

[8] Rupnik M, TambicAndrasevic A, Trajkovska Dokic E, et al. Distribution of Clostridiumdifficile PCR ribotypes and highproportion of 027 and 176 in some hospitals in four South Eastern European countries. Anaerobe. 2016 Dec; 42: 142-44. PMid:27751937. https://doi.org/10.1016/j.anaerobe.2016.10.005

[9] Institute of Public Health of Serbia. Annual Report of Communicable 
Diseases, 2011. Institute of Public Health of Serbia, Belgrade; 2012 (in Serbian).

[10] Institute of Public Health of Serbia. Annual Report of Communicable Diseases, 2013. Belgrade: Institute of Public Health of Serbia, 2014 (in Serbian).

[11] ECDC. Point prevalence survey of healthcare-associated infections and antimicrobial use in European acute care hospitals Protocol version 4.3. Stocholm: European Centre for infection prevention and Control; 2012

[12] Ministry of Healthof Republic of Serbia. Rulebook on Prevention, Early Detection and Control of Health care associate infections. Official Gazette of Republic of Serbia, 2015 (in Serbian).

[13] Suljagic V, Djorđević D, Lazic S, et al. Epidemiological Characteristics of Nosocomial Diarrhea Caused by Clostridium Difficile in a Tertiary Level Hospital in Serbia. Srp Arh Celok Lek. 2013 Jul-Aug; 141: 482-89. PMid:24073554. https://doi .org/10.2298/SARH $1308482 \mathrm{~S}$

[14] Dubberke ER, Reske KA, Yan Y, et al. Clostridium difficileassociated disease in a setting of endemicity: identification of novel risk factors. Clin Infect Dis. 2007 Dec; 45: 1543-9. https : //doi.org/10.1086/523582

[15] Pépin J, Valiquette L, Cossette B. Mortality attributable to nosocomial Clostridium difficile-associated disease during an epidemic caused by a hypervirulent strain in Quebec. CMAJ. 2005 Oct; 173: 1037-42. https://doi.org/10.1503/cmaj.050978

[16] Lango D. Clostridium difficile infections. New Engl J Med. 2015 Apr; 372: 1539-48.
[17] Al-Obaydi W, Smith CD, Foguet P. Changing prophylactic antibiotic protocol for reducing Clostridium difficile-associated diarrhoealinfections. J Orthop Surg. (Hong Kong). 2010 Dec; 18: 320-3. https://doi.org/10.1177/230949901001800312

[18] Qu HQ, Jiang ZD. Clostridium difficile infections in diabetes. Diabetes Res Clin Pract. 2014 Sep; 105: 285-94. https ://doi.org/ 10.1016/j.diabres.2014.06.002

[19] Ministry of Health of Republic of Serbia. Instruction for Prevention and Control of Hospital Infections caused by C. difficile. Official Gazette of Republic of Serbia, 2013 (in Serbian).

[20] Cohen S, Gerding D, Johnson S, et al. Society for Healthcare Epidemiology of America; Infectious Diseases Society of America: Clinical practice guidelines for Clostridium difficile infection in adults: 2010 update by the society for healthcare epidemiology of America (SHEA) and the infectious diseases society of America (IDSA) Infect Control Hosp. Epidemiol. 2010 May; 31: 431-55.

[21] Surawicz C, Brandt L, Binion D, et al. Guidelines for diagnosis, treatment, and prevention of Clostridium difficile infections. Am J Gastroenterol. 2013 Apr; 108: 478-498. https ://doi.org/10.1 038/ajg. 2013.4

[22] Davey P, Brown E, Charani E, et al. Interventions to improve antibiotic prescribing practices for hospital inpatients. Cochrane Database System Rev. 2013; 4: Cd003543. https ://doi .org/10.1002/14 651858. CD003543. pub3

[23] Feazel LM, Malhotra A, Perencevich EN, et al. Effect of antibiotic stewardship programmes on Clostridium difficile incidence: a systematic review and meta-analysis. J Antimicrob Chemother. 2014 Jul; 69: 1748-54. PMid:24633207. https://doi.org/10.1093/ $\mathrm{jac} / \mathrm{dku} 046$ 